\title{
Prevalencia de la infección genital por virus papiloma humano en hombres universitarios voluntarios de la IX Región, Chile
}

\author{
Pablo G uzmán ${ }^{1}$, Carmen Ilila, Patricio Rifo², Gastón Briceño², \\ Juan Araya ${ }^{1}$, Miguel Villaseca ${ }^{1}$, Juan Carlos Roa ${ }^{1}$. \\ Prevalence of human papillomavirus \\ genital infection among male \\ university students
}

Background: Human papillomavirus (HPV) infection is the most common sexually transmitted disease. Aim: To determine prevalence of HPV genital infection in voluntary asymptomatic male university students. Material and methods: A cross-sectional study in 62 asymptomatic, sexually active male students. Exfoliated cells were obtained from the penile shaft and coronal sulcus. Samples were analyzed for HPV DNA detection and genotyping by polymerase chain reaction and Reverse Line Blot. Results: The prevalence of HPV infection was $84 \%$. HPV detection was $77 \%$ in penile shaft and $66 \%$ in coronal sulcus. The most commonly detected types were HPV-16 (45\%), HPV-11 (19\%), HPV-6 (10\%) and HPV-18 (9\%). Multiple infection was found in 54\%. The most frequent combinations were VPH11/16 (18\%) and VPH16/18 (5\%). Conclusions: HPV infection is highly frequent in asymptomatic male university students, high risk HPV types were greatly predominant (Rev Méd Chile 2008; 136: 1381-9).

(Key words: Human papilloma virus; Oncogenic viruses; Uterine cervical neoplasms)

Recibido el 21 de diciembre, 2007. Aceptado el 15 de julio, 2008.

Trabajo financiado por Proyecto DI07-0088, de la Dirección de Investigación y Desarrollo de la Universidad de La Frontera.

${ }^{1}$ Departamento de Anatomía Patológica y ${ }^{2}$ Dermatología, Facultad de Medicina, Universidad de La Frontera, Temuco, Chile.

aTecnólogo Médico.

La a infección por virus papiloma humano (VPH) es la enfermedad de transmisión sexual más frecuente en el mundo ${ }^{1}$ y principal causa de los casos de carcinoma cervicouterino y lesiones precursoras; se le relaciona además, con tumores

Correspondencia a: Pablo Guzmán G. Departamento de Anatomía Patológica, Facultad de Medicina, Universidad de La Frontera. Fono-Fax: 045-296591.

E mail: pguzman@ufro.cl en otras localizaciones como cáncer de pene y otros epitelios anogenitales ${ }^{2}$.

El VPH es un virus ADN, de la familia Papillomaviridae, con más de doscientos tipos identificados y alrededor de 40 que afectan la región anogenital ${ }^{3,4}$. Según su oncogenicidad, se dividen en virus de bajo (BR) y alto riesgo (AR). Los VPH anogenitales más frecuentes en población masculina son similares a los informados en mujeres. Los principales tipos de VPH de BR son 
$6,11,42,52$ y 84 asociados a verrugas genitales y displasia leve cervicouterina. Los virus de AR más reportados son 16, 18, 31, 33, 52, 53 y 59 y se relacionan con displasia de alto grado y carcinoma cervicouterino, vagina, vulva, ano y pene ${ }^{1,5}$.

Existe abundante información de esta infección en mujeres, sin embargo, sus características en población masculina, son poco conocidas. Los tipos y distribución de los VPH genitales permanecen sin ser caracterizados, esto dificultado por ausencia de manifestaciones clínicas en la mayoría de los portadores, infecciones transitorias, ausencia de notificación obligatoria y falta de consenso respecto a métodos de obtención y procesamiento de muestras. Los métodos de detección de VPH en hombres, han mejorado progresivamente; inicialmente sólo se disponía de hallazgos clínicos e histológicos ${ }^{6,7}$, de baja sensibilidad y especificidad; luego se intentó cultivar el virus ${ }^{8}$ y detectarlo serológicamente ${ }^{9}$, con resultados poco alentadores. Actualmente, los más usados son técnicas moleculares basadas en PCR y la captura híbrida de segunda generación (CH II), este último es el único aceptado por la FDA (Food and Drug Administration $)^{10}$. El test $\mathrm{CH}$ II consiste en la síntesis y posterior captura de híbridos de ADN viral por medio de una sonda de ARN específica cuya reacción es detectada por quimioluminiscencia. Aunque es muy sensible, ella depende del contenido celular de las muestras, obteniéndose ocasionalmente falsos positivos y negativos y contaminaciones cruzadas entre tipos de AR y $\mathrm{BR}^{11}$. Las técnicas de PCR presentan ventajas frente a la $\mathrm{CH}$ II, ya que puede identificar tipos específicos de VPH y diferenciar infecciones por VPH de AR y BR ${ }^{12}$. Para recolectar las células exfoliadas se han utilizado tórulas de algodón, cepillos y papeles abrasivos ${ }^{13-17}$. Las muestras de orina se han usado, pero con resultados deficientes $^{18,19}$. Muestras de semen aportan cifras variables y sólo se justifica la pesquisa de VPH en bancos de donantes ${ }^{18,20}$. Las muestras también han sido guiadas previa pincelación de ácido acético y estudio colposcópico, lo que requiere personal experimentado para recolección de muestras, incomodidad para el paciente y aumento de los $\operatorname{costos}^{21}$. Los sitios de mayor detección son cuerpo de pene, surco coronal y escroto ${ }^{22}$. Sitios menos importantes son: uretra, semen, zona perianal y ano ${ }^{22-24}$.
En población similar a la de nuestro estudio, se han reportado cifras variables. En Kenia se informó $54 \%$ para población de 17 a 25 años ${ }^{25}$, en México 50\% para jóvenes asintomáticos de 20 a 29 años $^{14}$ y $48 \%$ para soldados de 21 a 24 años ${ }^{26}$. En estudiantes masculinos universitarios de Estados Unidos de Norteamérica se encontró $62 \% 27 ; 8,7 \%$ en Corea $^{28}$ y sólo 1,3\% en Japón ${ }^{29}$. En soldados conscriptos de Finlandia se publicó $9,1 \% 30$ y en Suecia $12 \% 31$.

El objetivo de este estudio es determinar, por primera vez en nuestro país, la prevalencia y tipificación de la infección genital por VPH en hombres universitarios voluntarios, asintomáticos, para aportar así, información epidemiológica básica que podría generar beneficios en población masculina como femenina para futuras estrategias de vacunación contra VPH y sus lesiones asociadas.

\section{MATERIAL Y MÉTODO}

Sujetos de estudio. Sesenta y dos estudiantes de sexo masculino, de carreras de la salud -Medicina, Odontología y Tecnología Médica- de la Facultad de Medicina de la Universidad de La Frontera, aparentemente sanos y sexualmente activos, aceptaron voluntariamente la invitación a participar y debieron dar su aprobación por escrito mediante consentimiento informado. El estudio fue aprobado por el Comité de Ética de la Facultad de Medicina de la Universidad de La Frontera. Se utilizó una encuesta autoaplicada sobre características sociodemográficas y de comportamiento sexual. Se obtuvo muestras de células exfoliativas del cuerpo del pene y surco coronal frotando una tórula estéril en dichas áreas. La tórula se depositó en $1 \mathrm{ml}$ de buffer de lisis $\mathrm{pH} 7,4$ a $4^{\circ} \mathrm{C}$ hasta su procesamiento.

Extracción de ADN. Las muestras se transfieren a tubos de 1,5 mL. Las proteínas fueron precipitadas con acetato de amonio $5 \mathrm{M} \mathrm{pH} \mathrm{7,5.} \mathrm{Al}$ sobrenadante se le agregó $600 \mu \mathrm{L}$ de isopropanol y $1 \mu \mathrm{L}$ de glicógeno $(20 \mu \mathrm{g} / \mu \mathrm{L})$ y se incubó toda la noche para precipitar el ADN. El ADN obtenido se lavó con etanol 70\% y se resuspendió con $30 \mu \mathrm{L}$ de agua destilada estéril, siendo conservado a $-20^{\circ} \mathrm{C}$. 
Controles para reacción de polimerasa en cadena (PCR). A todas las muestras se les realizó amplificación del gen humano ß-globina (fragmento de $268 \mathrm{pb}$ ) para confirmar la adecuada extracción de ADN. A los individuos con muestras negativas para ß-globina se les repitió la toma de muestra por una vez. Como control negativo del PCR específico para VPH se empleó ADN genómico humano (Promega) y como blanco se utilizó mezcla de PCR sin ADN. Como controles positivos para Reverse Line Blot (RLB) se emplearon mezclas de productos de PCR de plásmidos virales solicitados al ATCC (American Type Culture Collection) conteniendo secuencias de VPH 6, 11, 16, 18, 33, $35,45,52,56,58,66$ y 70, probados previamente en diluciones de 100, 50, 10 y $5 \mathrm{pmol} / \mu \mathrm{L}$, para determinar la sensibilidad del método.

Detección de VPH. Se realizó mediante PCR con partidores GP5+y bioGP6+, que permiten amplificar un fragmento de $150 \mathrm{bp}$ del gen L1 del virus y detectar VPH de AR $[16,18,26,31,33,35,39,45$, $51,52,53,56,58,59,66,68,73$ y 82 subtipos IS39 y W13B/MM4] y de BR [6, 11, 34, 40, 42, 43, 44, 54, 55, 57, 61, 70, 71, 72, 81, 83, 84 у CP6108] y además permite la marcación del producto de PCR con biotina.

Tipificación de VPH. Se realizó mediante RLB, utilizando sondas de nucleótidos complementarias a cada tipo viral que se unen a una membrana de nylon de carga negativa, contenida en un sistema de Miniblotter (Immnunetics). Posteriormente, se cargan los productos de PCR biotinilados con los iniciadores GP5+ y bioGP6+, de forma perpendicular a la que se agregaron las sondas. En los puntos donde se interceptan los productos con las sondas, se genera una hibridación evidenciada al agregar el complejo streptavidina-peroxidasa. Luego esta hibridación se visualiza por quimioluminiscencia en una película (Hyperfilm).

Estadística. Los análisis se realizaron con el programa Stata 10.0. Un caso se consideró positivo si en al menos una de las dos muestras se detectó VPH. Las tablas de contingencia de VPH y su relación con características sociodemográficas y de comportamiento sexual fueron analizadas utilizando test exacto de Fisher. Se consideró como significativo un valor de $\mathrm{p}$ menor a 0,05 .

\section{RESULTADOS}

Características del grupo. El promedio de edad fue de 22,8 años (rango: 20 a 51 años). Todos los voluntarios eran heterosexuales, con examen físico genital normal, no circuncidados, alumnos regulares principalmente de las carreras de Medicina y Odontología y 79\% cursaban tercer o cuarto año. La mayoría (97\%) era soltero, ingería alcohol ocasional, sin antecedentes de hábito tabáquico ni historia de ETS. El 95\% del grupo inició sus relaciones sexuales después de los 15 años, había tenido entre 1 a 5 parejas sexuales durante su vida (85\%), una pareja sexual en un mismo mes (92\%), el uso de preservativo con su pareja habitual fue sólo ocasional o no lo utilizó (86\%). La Tabla 1 detalla las características de los individuos positivos para infección por VPH. No se encontraron diferencias estadísticamente significativas entre características sociodemográficas o hábitos sexuales y la detección de VPH.

Detección de VPH. Un caso resultó negativo para ß-globina siendo excluido del estudio. De los 61 estudiantes, 51 (84\%) resultaron positivos para $\mathrm{VPH}$, en 5 (8\%) se detectó únicamente VPH BR, 20 (33\%) individuos sólo poseían VPH de AR y 26 (43\%) tenían una infección mixta.

Tipificación de VPH. De los 13 genotipos virales identificados, $70 \%$ correspondió a genotipos de AR, siendo los más frecuentes el $16(45 \%), 18$ (9,4\%), 45, 52, 59 (2,7\% cada uno), 56 (2\%), 35, 66 (1,3\% cada uno), 39 y 58 (0,7\% cada uno). El 30\% eran de BR y correspondieron a genotipo 11 $(19,5 \%), 6(10,1 \%)$ y $81(0,7 \%)$. El genotipo más frecuente, VHP 16, se encontró de manera exclusiva en $43 \%$, asociado a un genotipo de BR en $28 \%$, en $16 \%$ junto a otro genotipo de AR y en $12 \%$ asociado a genotipos de AR y BG. La Figura 1 grafica la prevalencia de los genotipos de VPH encontrados. La Figura 2 muestra la distribución de los diversos tipos detectados relacionados con el sitio de muestreo, no encontrándose diferencias significativas en esta relación.

La Tabla 2 presenta el resultado de los genotipos de VPH. El 30\% de los estudiantes (23\% de los casos positivos) presentaba una infección simple, que correspondía principalmente a VPH 16. Las infecciones múltiples, tuvieron 16 combinaciones 
Tabla 1. Características sociodemográficas y de comportamiento sexual de los 51 casos positivos deVPH genital

\begin{tabular}{|c|c|c|c|c|c|c|}
\hline \multirow{3}{*}{ Edad (años) } & \multicolumn{4}{|c|}{ Tipo de Infección (№ (\%)) } & \multirow{2}{*}{\multicolumn{2}{|c|}{ Infección mixta }} \\
\hline & \multicolumn{2}{|c|}{ VPH +} & \multicolumn{2}{|c|}{ VPH AR } & & \\
\hline & & & & & & \\
\hline $20-22$ & 33 & (65) & 14 & (70) & 17 & (65) \\
\hline $23-25$ & 14 & (27) & 4 & (20) & 8 & (31) \\
\hline$>25$ & 4 & (8) & 2 & (10) & 1 & (4) \\
\hline \multicolumn{7}{|l|}{ Carrera } \\
\hline Medicina & 28 & (55) & 10 & (50) & 15 & (58) \\
\hline Odontología & 17 & (33) & 7 & (35) & 9 & (35) \\
\hline Tecnología Médica & 6 & (12) & 3 & (15) & 2 & (8) \\
\hline \multicolumn{7}{|l|}{ Curso } \\
\hline Tercer año & 23 & (45) & 10 & (50) & 12 & (46) \\
\hline Cuarto año & 18 & (35) & 4 & (20) & 13 & (50) \\
\hline$>$ Cuarto año & 10 & (20) & 6 & (30) & 1 & (4) \\
\hline \multicolumn{7}{|l|}{ Estado civil } \\
\hline Soltero & 50 & (98) & 20 & $(100)$ & (25) & 96 \\
\hline Casado & 1 & (2) & 0 & (0) & (1) & 4 \\
\hline \multicolumn{7}{|l|}{ Ingesta de alcohol } \\
\hline $\mathrm{Si}$ & 40 & (78) & 15 & $(75)$ & 22 & $(85)$ \\
\hline No & 11 & (22) & 5 & (25) & 4 & (15) \\
\hline \multicolumn{7}{|l|}{ Hábito tabáquico } \\
\hline $\mathrm{Si}$ & 17 & (33) & 7 & (35) & 7 & (27) \\
\hline No & 34 & (67) & 13 & (65) & 19 & (73) \\
\hline \multicolumn{7}{|l|}{ Antecedente de ETS } \\
\hline $\mathrm{Si}$ & 2 & (4) & 1 & (5) & 0 & (0) \\
\hline \multicolumn{7}{|l|}{ Edad de la primera relación sexual } \\
\hline Antes de 15 años & 3 & (6) & 1 & (5) & 1 & (4) \\
\hline Entre 15 y 18 años & 25 & (49) & 10 & (50) & 12 & (46) \\
\hline Después de 18 años & 23 & (45) & 9 & (45) & 13 & (50) \\
\hline \multicolumn{7}{|l|}{ Número de parejas sexuales durante la vida } \\
\hline $1-5$ & 44 & (86) & 19 & (95) & 21 & (81) \\
\hline $6-20$ & 6 & (12) & 1 & (5) & 4 & (15) \\
\hline Más de 20 & 1 & (2) & 0 & (0) & 1 & (4) \\
\hline \multicolumn{7}{|l|}{ Número de parejas sexuales en el último año } \\
\hline 0 & 2 & (4) & 1 & (5) & 1 & (4) \\
\hline 1 & 39 & (76) & 12 & (60) & 22 & (85) \\
\hline 2 y más & 10 & (20) & 7 & (35) & 3 & (12) \\
\hline \multicolumn{7}{|l|}{ Número de parejas sexuales en un mismo mes } \\
\hline 1 & 49 & (96) & 18 & (90) & 26 & (100) \\
\hline \multirow{2}{*}{\multicolumn{7}{|c|}{ Número de parejas sexuales de su pareja habitual }} \\
\hline & & & & & & \\
\hline Desconocido & 11 & (22) & 6 & (30) & 3 & (12) \\
\hline 1 & 36 & (71) & 14 & (70) & 20 & (77) \\
\hline 2 y más & 4 & (8) & 0 & (0) & 3 & (12) \\
\hline \multicolumn{7}{|l|}{ Uso de preservativo con pareja habitual } \\
\hline Siempre & 8 & (16) & 3 & (15) & 3 & (12) \\
\hline Ocasional & 29 & (57) & 10 & (50) & 16 & (62) \\
\hline Nunca & 14 & (27) & 7 & (35) & 7 & (27) \\
\hline Relaciones sexuales con prostitutas & & & & & & \\
\hline No & 50 & (98) & 20 & $(100)$ & 25 & (96) \\
\hline $\mathrm{Si}$ & 1 & (2) & 0 & (0) & 1 & (4) \\
\hline Aseo genital después de relación sexual & & & & & & \\
\hline Nunca & 4 & (8) & 2 & (10) & 1 & (4) \\
\hline Siempre & 26 & (51) & $1 \overline{1}$ & (55) & 13 & (50) \\
\hline Ocasional & 21 & (41) & 7 & (35) & 12 & (46) \\
\hline
\end{tabular}




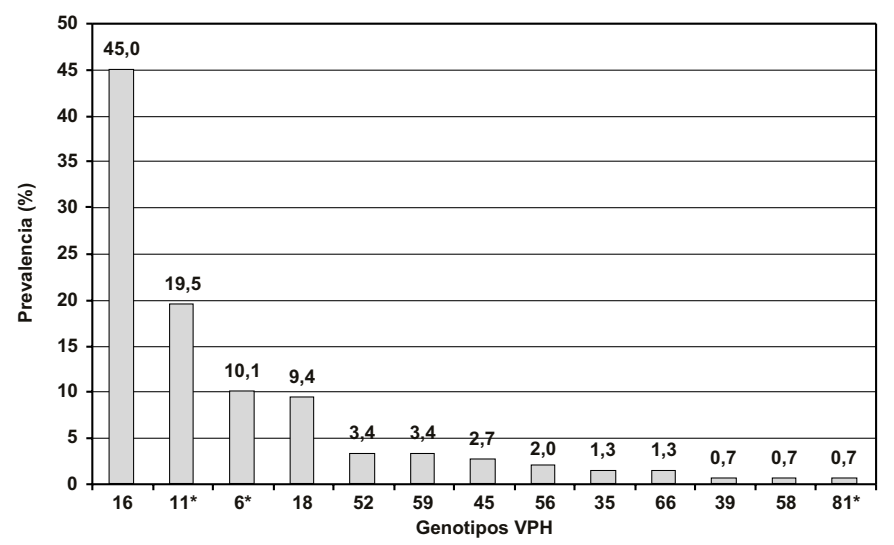

Figura 1. Distribución de genotipos de VPH en el total de individuos positivos para infección por VPH. (*Bajo riesgo oncogénico).

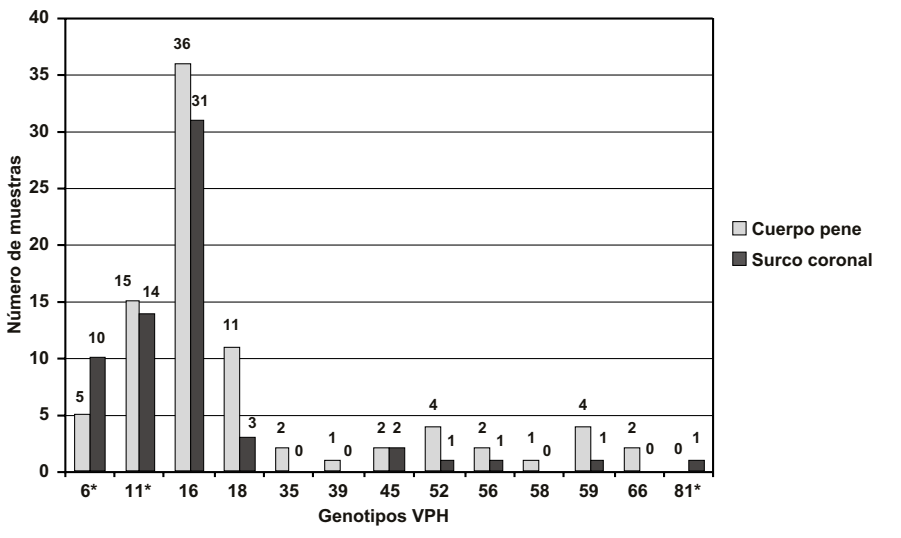

Figura 2. Distribución de genotipos de VPH y su relación con el sitio de toma de muestra. (*Bajo riesgo oncogénico).

de VPH de BR y AR y 5 asociaciones entre dos o más VPH de AR. No se encontraron combinaciones de VPH de bajo riesgo. Las asociaciones más frecuentes entre VPH de BR y AR fueron VPH11/ 16 (18\%), VPH16/18 (3\%) y VPH11/16/18 (3\%) y la más frecuente entre VPH de AR fue VPH 16/18 $(5 \%)$.

Análisis según sitio de muestreo. La muestra de cuerpo de pene resultó positiva para VPH en $77 \%$, y $46 \%$ eran VPH de AR. La muestra de surco coronal tuvo $66 \%$ de positividad, con detecciones similares, para VPH de AR (26\%) y mixtas (30\%).
Ambos sitios tuvieron una muestra negativa para ß-globina $(1,6 \%)$. La mayor concordancia diagnóstica, entre ambos sitios, se registró para casos negativos y positivos VPH de AR. El cálculo de kappa cuadrática, entre los resultados de ambos sitios de toma de muestra, resultó 0,4 (correlación moderada).

\section{DisCUSIÓN}

En el presente estudio logramos demostrar una alta prevalencia de la infección genital por VPH 
Tabla 2. D istribución y combinación de genotipos deVPH en el total de estudiantes positivos para infección por VPH

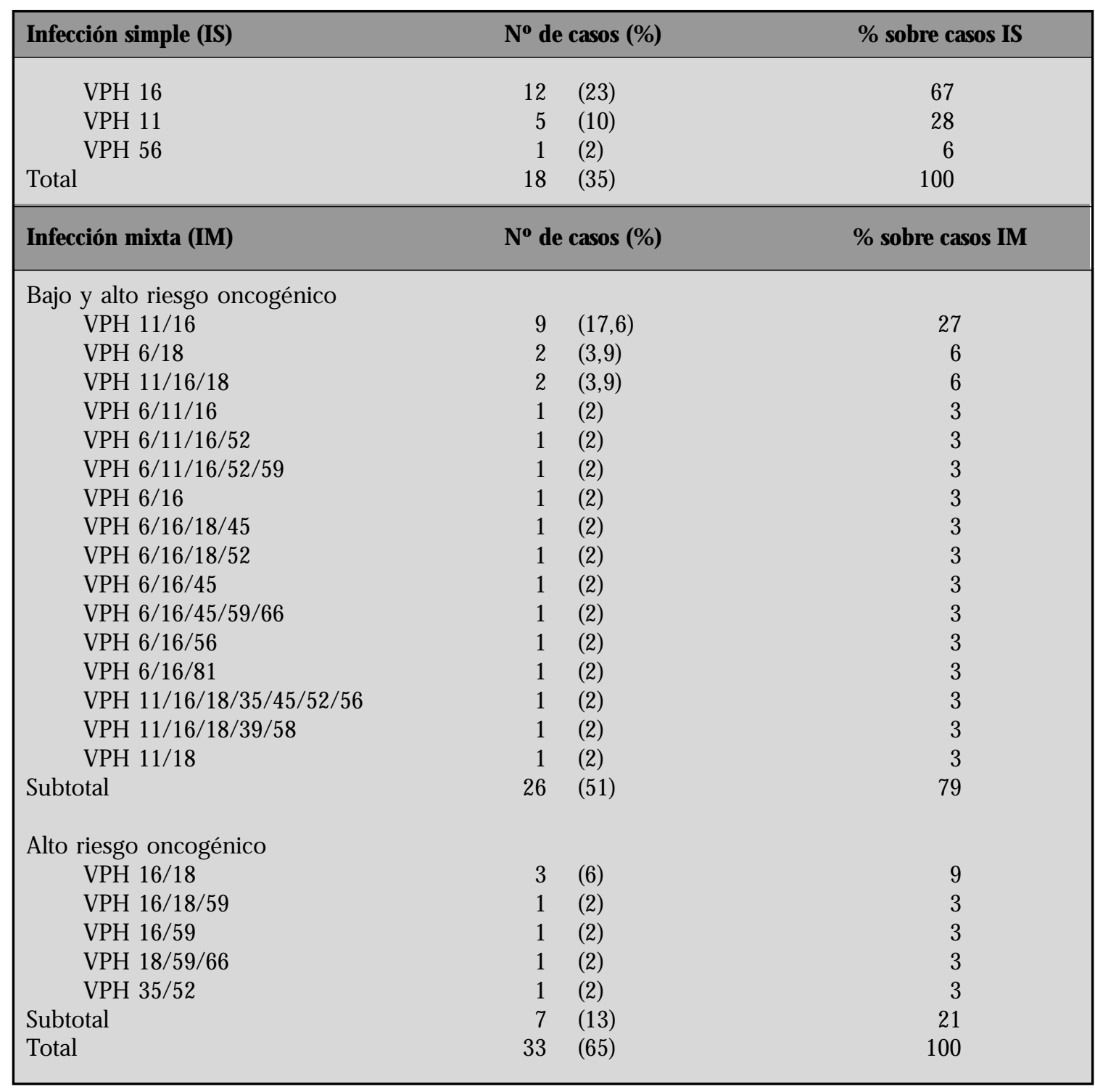

en hombres universitarios voluntarios de la IX Región (84\%). Esta alta cifra puede estar influida por un sesgo de selección en el tipo de individuos evaluados -estudiantes autoseleccionados- y la alta sensibilidad del método empleado. De interés resulta destacar, que el valor encontrado, se acerca al observado en detección de $\mathrm{VPH}$ en mujeres de la IX Región, con lesión cervical intraepitelial de bajo grado (88\%), de alto grado (89\%) y carcinoma invasor $(93,5 \%)^{32}$.

La prevalencia publicada para infección genital por VPH en población masculina varía de 1,3\% a $72,9 \%{ }^{1}$. Estas diferencias estarían dadas por la edad y conductas sexuales de los individuos analizados, sitio de muestreo, sensibilidad de los sistemas de detección y existencia de áreas endémicas para 
tipos específicos de $\mathrm{VPH}^{26}$. En estudiantes universitarios se publican cifras de $1,3 \%$ a $43 \% 29,33$; en parejas masculinas de mujeres con VPH o con lesiones preneoplásicas cervicouterinas se encontraron cifras de $70 \%{ }^{34}$ y $72,9 \% 35$, respectivamente; en pacientes con cáncer de pene ${ }^{36}$ y hombres atendidos por ETS ${ }^{37}$ se encontró en $50 \%$ y en población militar masculina $44,6 \% 26$. En mujeres, estudios metaanalíticos, revelan prevalencia de VPH en pacientes con cáncer cervicouterino que oscila entre $79 \%$ a $88 \%$ según área geográfica ${ }^{38}$, a nivel nacional se han publicado cifras de 11,2\% para pacientes con citología cervical normal y $55,9 \%$ con citología alterada ${ }^{39}$. Respecto a la evolución de la infección, en mujeres se ha visto que a pesar de ser muy frecuente, es altamente transitoria, con eliminación de hasta $77 \%$ en menos de dos años ${ }^{40}$. Los escasos trabajos en población masculina, han encontrado -en soldados mexicanos- $54 \%$ de eliminación de infección y persistencia de $30 \%$ en un año de seguimiento 26 .

Con respecto a los tipos de VPH detectados, la prevalencia para virus de AR (33\%) es mayor que para tipos de BR (8\%), lo que concuerda con lo publicado, con rangos de $2 \%$ a $35 \%$ para AR y $2 \%$ a $24 \%$ para $\mathrm{BR}^{41}$. El VPH 16 es el genotipo más frecuente, seguido por los tipos 6, 11 y 18. Idéntica distribución a la nuestra, se encontró en individuos circuncidados y no circuncidados ${ }^{42}$. La mitad de los individuos (43\%) presentan infección múltiple, reportándose cifras de hasta $51,1 \% 26$. Resulta también interesante mencionar que los genotipos de VPH de AR encontrados (VPH 16, 18,52 y 59) son idénticos a los detectados con mayor frecuencia en población femenina local, con lesión preneoplásica cervicouterina ${ }^{43}$, lo que reforzaría los conceptos de variación en distribución geográfica de VPH y la presencia de determinadas condiciones locales y genéticas del huésped que afectarían el comportamiento biológico viral.

Respecto del sitio de muestreo, la mayoría estudia y recomienda surco coronal, prepucio o cuerpo de pene basados en su fácil acceso, recolección sencilla y buena tolerancia al procedimiento ${ }^{1,22}$. Nuestras cifras de $77 \%$ y $66 \%$ para cuerpo de pene y surco coronal, respectivamente, aunque mayores a otros autores, corroboran la adecuada pesquisa en estos sitios.

En publicaciones destinadas a detectar factores de riesgo, mediante análisis multivariado de facto- res independientes, ajustando por elementos confundentes, se ha encontrado una relación inversa entre infección por VPH y edad del individuo, uso de preservativo y en circuncidados y una relación directa con número de parejas sexuales y frecuencia de relaciones sexuales. Factores de riesgo asociados de manera directa con infecciones por VPH BR son juventud del individuo, historia o presencia de verrugas genitales y número de parejas sexuales ${ }^{15,17}$.

Respecto al método de detección utilizado, la tipificación de VPH mediante PCR-RLB presenta varias ventajas, entre ellas, el análisis en una misma membrana de a lo menos 40 muestras problema, siendo capaz de discriminar hasta 38 genotipos virales a la vez, lo cual no ocurre con $\mathrm{CH}$ II y enzimainmunoensayo (EIA), las que sólo pueden diferenciar entre virus de $\mathrm{AR}$ y $\mathrm{BR}^{44}$. El método de PCR-RLB es de fácil realización y relativamente barato, a diferencia de otras costosas técnicas como Real-Time PCR o PCR seguida de restricción enzimática (PCR-RFLP), de difícil interpretación, sobre todo en infecciones múltiples ${ }^{43}$. Se han reportado estudios de pesquisa de VPH, en donde PCR-RLB se compara con otras técnicas -EIA y CH II-, en donde el RLB ha mostrado gran especificidad y excelente sensibilidad, muy similar o levemente superior que los otros métodos ${ }^{44,45}$.

En resumen, podemos afirmar que la infección por VPH en hombres universitarios voluntarios asintomáticos de la IX Región es muy frecuente, predominando los genotipos de AR, en especial el VPH 16. La consecuencia de esta infección posee un doble significado, la más inmediata es la transmisión a las parejas sexuales con el potencial desarrollo de procesos neoplásicos genitales y, a largo plazo, también este mismo tipo de lesiones, podrían llegar a desarrollarse en individuos portadores. Es de suma importancia obtener mayor información científica respecto de la infección por VPH en hombres, la que podría utilizarse en futuras estrategias de prevención, control y tratamiento de neoplasias asociadas a VPH en mujeres y hombres.

\section{Agradecimientos}

Los autores agradecen a los estudiantes de la Facultad de Medicina de la Universidad de La Frontera que aceptaron participar e hicieron posible la ejecución de este estudio. 


\section{REFERENCIAS}

1. Dunne E, Nielson C, Stone K, Markowitz L, Giuluano R. Prevalence of HPV infection among men: A systematic review of the literature. J Infect Dis 2006; 194: 1044-57.

2. Bosch F, Rohan T, Schneider A, Frazer I, Pfister H, Castellsague X et al. Papillomavirus research update: highlights of the Barcelona HPV 2000 international papillomavirus conference. J Clin Pathol 2001; 54: 163-75.

3. De Viluers E, Fauquet C, Broker T, Bernard H, Zur HAUSEN H. Classification of papillomaviruses. Virology 2004; 324: 17-27.

4. BERNARD H. The clinical importance of the nomenclature, evolution and taxonomy of human papillomaviruses. J Clin Virol 2005; 32: S1-S6.

5. MuÑoz N. Human papillomavirus and cancer: the epidemiological evidence. J Clin Virol 2000; 19: 1-5.

6. Strand A, Rytander E, Witander E, Zehbe I, Kraaz W. Histopathologic examination of penile epithelial lesions is of limited diagnostic value in human papillomavirus infection. Sex Transm Dis 1996; 23: 293-8.

7. KreBs B, SCHNEIDER V. Human papillomavirus-associated lesions of the penis: colposcopy, cytology, and histology. Obstet Gynecol 1987; 70: 299-304.

8. Siegel F, MeLunger C. Human papillomavirus in the male patient. Urol Clin North Am 1992; 19: 83-91.

9. Clifford M, Shin $\mathrm{H}, \mathrm{OH} \mathrm{J}, \mathrm{W}_{\text {aterboer }} \mathrm{T}$, Ju $\mathrm{Y}$, VACCARELIA S ET aL. Serologic response to oncogenic human papillomavirus types in male and female university students in Busan, South Korea. Cancer Epidemiol Biomarkers Prev 2007; 16: 1874-9.

10. Sailors J, Gander R, Saboorian H, Berkiey P, Foster B, AsHFaQ R. Stability of PreservCyt for Hybrid Capture (HC II) HPV test. Diagn Cytopathol 2005; 32: 260-3.

11. Yamazaki H, Sasagawa T, Basha W, Segawa T, Inoue M. Hybrid capture-II and LCR-E7 PCR assays for HPV typing in cervical cytologic simples. Int J Cancer 2001; 94: 222-7.

12. MoljN A, KieTer B, Quint W, van Doorn J. Molecular diagnosis of human papillomavirus (HPV) infections. J Clin Virol 2005; 32: S43-S51.

13. Wikstrom A, Popescu C, Forslund O. Asymptomatic penile HPV infection: a prospective study. Int J STD AIDS 2000; 11: 80-4.

14. Lazcano-Ponce E, Herrero R, Munoz N, HernándezAvila M, Salmeron J, Leyva A et al. High prevalence of human papillomavirus infection in Mexican males: comparative study of penile-urethral swabs and urine samples. Sex Transm Dis 2001; 28: 277-80.

15. Baldwin B, Wallace R, Papenfuss R, Abrahamsen M, Vaught C, Kornegay R et al. Human papillomavirus infection in men attending a sexually transmitted disease clinic. J Infect Dis 2003; 187: 1067-70.
16. Greer E, Wheeler M, Ladner B, Beutner K, Coyne $Y$, LANG H ET aL. Human papillomavirus (HPV) type distribution and serological response to HPV type 6 virus-like particles in patients with genital warts. J Clin Microbiol 1995; 33: 2058-63.

17. Svare I, Kjaer K, Worm M, Osterlind A, Meijer J, van DEN BRULE J. Risk factors for genital HPV DNA in men resemble those found in women: a study of male attendees at a Danish STD clinic. Sex Transm Infect 2002; 78: 215-8.

18. Astori G, Pipan C, Muffato G, Botta A. Detection of HPV-DNA in semen, urine and urethral samples by dot blot and PCR. New Microbiol 1995; 18: 143-149.

19. Geddy M, Wells M, LACEy J. Lack of detection of human papillomavirus DNA in male urine samples. Genitourin Med 1993; 69: 276-9.

20. Aynaud O, Poveda D, Huynh B, Guilemotonia A, BARRASSO R. Frequency of herpes simplex virus, cytomegalovirus and human papillomavirus DNA in semen. Int J AIDS 2002; 13: 547-50.

21. Hippelainen I, Syrjanen S, Hippeiainen J, Saarikoski S, SyRjanen K. Diagnosis of genital human papillomavirus (HPV) lesions in the male: correlation of peniscopy, histology and in situ hybridisation. Genitourin Med 1993; 69: 346-51.

22. Giulano R, Nielson M, Flores R, Dunne F, Abrahamsen M, PAPenfuss R ET AL. The optimal anatomic sites for sampling heterosexual men for human papillomavirus (HPV) detection: the HPV detection in men study. J Infect Dis 2007; 196: 1146-52.

23. Weaver A, Feng Q, Holmes K, Kiviat N, Lee K, Meyer C ET AL. Evaluation of genital sites and sampling techniques for detection of human papillomavirus DNA in men. J Infect Dis 2004; 189: 677-85.

24. Aguilar V, Lazcano-Ponce E, Vaccarella S, Cruz A, HeRnández P, Smith S et al. Human papillomavirus in men: comparison of different genital sites. Sex Transm Infect 2006; 82: 31-3

25. Smith J, Moses S, Hudgens G, Agot K, Franceschi S, Maciean W, NdinYa-Achola O. Human papillomavirus detection by penile site in young men from Kenya. Sex Transm Dis 2007; 34: 928-34.

26. Lajous M, Mueler N, Cruz-Vaidez A, Aguitar V, Franceschi S, Hernandez-Avita M et al. Determinants of prevalence, acquisition, and persistence of human papillomavirus in healthy Mexican military men. Cancer Epidemiol Biomarkers Prev 2005; 14: 1710-16.

27. Partridge J, Hughes J, Feng Q, Winer R, Weaver B, Xi L ET AL. Genital human papillomavirus infection in men: incidence and risk factors in a cohort of university students. J Infect Dis 2007; 196: 1128-36.

28. Shin H, Franceschi S, Vaccarelia S, Roh J, Ju Y, Oh J et AL. Prevalence and determinants of genital infection with papillomavirus, in female and male university students in Busan, South Korea. J Infect Dis 2004; 190: $468-76$. 
29. TAKahashi S, Shimizu T, Takeyama K, Kunishima $Y$, HotTA H, KorokU M ET AL. Detection of human papillomavirus DNA on the external genitalia of healthy men and male patients with urethritis. Sex Transm Dis 2003; 30: 629-33.

30. Hippelainen M, Syrjanen S, Hippeiainen M, Koskeia H, Pulkkinen J, SaArikoski S et al. Prevalence and risk factors of genital human papillomavirus (HPV) infections in healthy males: a study on Finnish conscripts. Sex Transm Dis 1993; 20: 321-8.

31. Forslund O, Hansson G, Rymark P, Bjerre B. Human papillomavirus DNA in urine samples compared with that in simultaneously collected urethra and cervix simples. J Clin Microbiol 1993; 31: 1975-9.

32. Melo A, Montenegro S, Hooper T, Capurro I, Roa J, RoA I. Tipificación del virus papiloma humano (VPH) en lesiones preneoplásicas y carcinoma del cuello uterino en mujeres de la IX región-Chile. Rev Méd Chile 2003; 131: 1382-90.

33. Hernández $Y$, McDufFe $K$, Goodman $T$, Wilkens $R$, THOMPson P, ZHu X ET AL Comparison of physician- and self-collected genital specimens for detection of human papillomavinus in men. J Clin Microbiol 2006; 44: 513-7.

34. Nicolau M, Camargo G, Stavale N, Castelo A, Dores B, LoRINCZ A ET AL. Human papillomavirus DNA detection in male sexual partners of women with genital human papillomavirus infection. Urology 2005; 65: 251-5.

35. Bieeker C, Hogewoning J, Berkhof J, Voorhorst J, HESSELINK T, van DIEMEN M ET AL. Concordance of specific human papillomavirus types in sex partners is more prevalent than would be expected by chance and is associated with increased viral loads. Clin Infect Dis 2005; 41: 612-20.

36. PALEFSKY J. HPV infection in men. Disease Markers 2007; 24: 261-72.

37. Wikstrom A, Lidbrink P, Johansson B, von Krogh G. Penile human papillomavirus carriage among men attending Swedish STD clinics. Int J STD AIDS 1991; 2: $105-9$

38. Clifford M, Smith J, Plummer M, Muñoz N, Franceschi S. Human papillomavirus types in invasive cervical cancer worldwide: a meta-analysis. Br J Ca 2003; 88: 63-73.

39. Ferreccio C, Prado R, Luzoro A, Ampuero S, Snijders P, MeIJER C ET AL. Population-Based prevalence and age distribution of human papillomavirus, among women in Santiago, Chile. Cancer Epidemiol Biomarkers Prev 2004; 13: 2271-6.

40. Oн K, Ju H, Franceschi S, Quint W, Shin H. Acquisition of new infection and clearance of type-specific human papillomavirus infections in female students in Busan, South Korea: a follow-up study. BMC Infect Dis 2008; 8: 13.

41. Partridge M, Koutsky A. Genital human papillomavirus infection in men. Lancet Infect Dis 2006; 6: 21-31.

42. Castellsague X, Bosch X, Muñoz N, Meijer J, Shah V, de SAN José S ET AL. Male circumcision, penile human papillomavirus infection, and cervical cancer in female partners. N Engl J Med 2002; 346: 1105-12.

43. Aedo S, Melo A, García P, Guzmán P, Capurro I, Roa J. Detección y tipificación de virus papiloma humano en lesiones del cuello uterino mediante PCR-RFLP. Rev Méd Chile 2007; 135: 167-73.

44. Van den Brule J, Pol R, Fransen-Daalmejer N, Schouls L, Meijer C, Snjuders J. GP5+/6+ PCR followed by reverse line blot analysis enables rapid and highthroughput identification of human papillomavirus genotypes. J Clin Microbiol 2002; 40: 779-87.

45. Soderlund-Strand A, Rymark P, Andersson P, Diluner J, DiLner L. Comparison between the Hybrid Capture II test and a PCR-based human papillomavirus detection method for diagnosis and posttreatment follow-up of cervical intraepithelial neoplasia. J Clin Microbiol 2005; 43: 3260-6. 